\title{
HIGHLY FUNCTIONAL POLYOLS FROM CASTOR OIL FOR RIGID POLYURETHANES
}

Mihail Ionescu*, Dragana Radojčić*, Xianmei Wan*, Maha Laxmi Shrestha*, Zoran S. Petrović* and Thomas Upshaw**

*Pittsburg State University, Kansas Polymer Research Center, Pittsburg, Kansas, 66762.

**Chevron Phillips Chemical Company LP, Bartlesville Technology Center, Bartlesville, OK 74003-6670.

\section{Correspondence address}

Zoran Petrović

Pittsburg State University,

Kansas Polymer Research Center,

1701 South Broadway,

Pittsburg, KS, 66762

E-Mail: zpetrovic@pittstate.edu

Telephone: (620) 235-4928

Fax: (620)-235-4049 


\begin{abstract}
Novel high hydroxyl number and high functionality polyols were developed using thiol-ene reaction of castor oil with mercaptoethanol or mercaptanized castor oil with allyl alcohol (by photochemical reaction) and 2-hydroxyethyl acrylate (by Michael thiol-ene reaction). The polyols had $\mathrm{OH}$ numbers of $220-295 \mathrm{mg} \mathrm{KOH} / \mathrm{g}$ and functionalities close to 6 . Cast polyurethane resins were prepared with methylene diphenyl diisocyanate (MDI), dicyclohexylmethane-4,4'diisocyanate (HMDI) and m-xylylene diisocyanate (XDI). XDI gave rubbery to leathery polyurethanes with all three polyols, while MDI and HMDI gave amorphous glasses with good mechanical properties. Rigid polyurethane foams of good properties were made with MDI and three castor oil-based polyols.
\end{abstract}

KEY WORDS: castor oil, polyols, thiol-ene, polyurethane foams. 


\section{INTRODUCTION}

Polyurethanes are the most versatile polymers used in foams, coatings, adhesives, sealants, elastomers, fibers and as casting compounds [1]. The advantage of these materials is that they can be tailored by the final user to meet a wide range of specific requirements. Thus, it is not surprising that some of the early attempts to convert renewable resources to polymers were in the area of polyurethanes [2,3]. Polyurethanes are made from isocyanates and polyols. Currently only few bio-based isocyanates are commercially available and the main focus has been designing polyols for specific polyurethane applications [4]. Preparation of polyurethanes from renewable raw materials is important from ecological, economic and technological standpoints [5-14]. Castor oil is a natural polyol with many applications in the polymer industry, particularly in polyurethanes (PU) [15-18].

The structure of castor oil is usually presented as triricinolein as in Scheme 1, but the content of ricinoleic acid is around 90\% the rest being oleic and linoleic acid as major components. Ricinoleic acid has a hydroxyl group on the $12^{\text {th }}$ carbon and a double bond between the $9^{\text {th }}$ and $10^{\text {th }}$ carbons. Castor oil has on average 2.7 hydroxyls per triglyceride and an $\mathrm{OH}$ number of $160-$ $168 \mathrm{mg} \mathrm{KOH} / \mathrm{g}$ [17]. Due to the presence of double bonds, castor oil is liquid at room temperature, having a viscosity of $700 \mathrm{mPa} \cdot \mathrm{s}$ at $25{ }^{\circ} \mathrm{C}$ and around $1000-1500 \mathrm{mPa} \cdot \mathrm{s}$ at $20{ }^{\circ} \mathrm{C}$ [17]. Hydrogenated castor oil is solid, with a melting point of $86^{\circ} \mathrm{C}$ [18]. Castor oil is a mixture of triols (70\%), diols (21\%) and monols (about 7\%). When crosslinked with methylene diphenyl diisocyanate (MDI) it gives a hard elastomer with a glass transition $\left(\mathrm{T}_{\mathrm{g}}\right)$ of $10{ }^{\circ} \mathrm{C}[16]$.
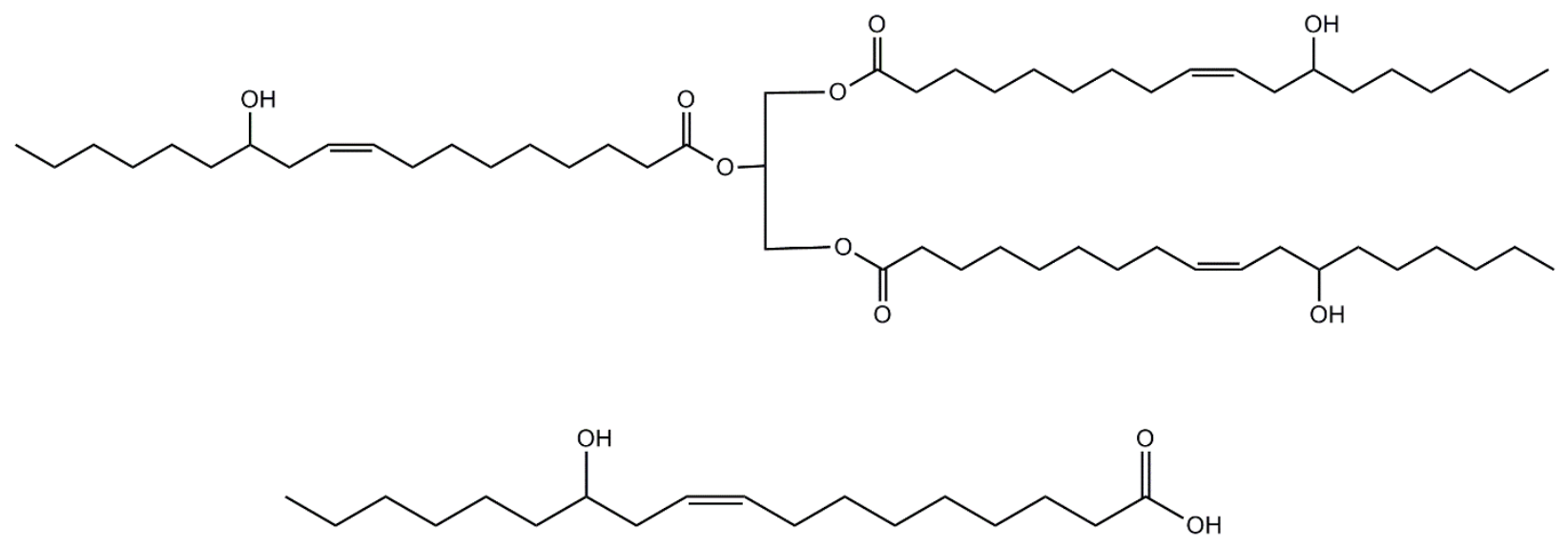

Scheme 1. Structures of castor oil and ricinoleic acid. 
In order to use castor oil for rigid applications such as rigid polyurethane foams, composites and cast compounds, the functionality of castor oil must be increased. An elegant way to achieve this is to use thiol-ene chemistry [19-35] for direct introduction of hydroxyls [26-35]. There are a limited number of published papers on polyols prepared by thio-ene reaction with castor oil. A patent [27] describes the thiol-ene addition of 2-mercaptoethanol to many vegetable oils, including castor oil but no examples or properties of a castor oil polyol are given.

In this work we have prepared three polyols from castor oil with high $\mathrm{OH}$ values using reactions of mercaptan (thiol) groups (-SH) with compounds having double bonds and hydroxyls. The first polyol was prepared by radical thiol-ene addition of 2-mercaptoethanol to castor oil. In the other two polyols, the starting material was mercaptanized castor oil, which underwent reaction with allyl alcohol or 2-hydroxyethyl acrylate. Replacement of the mercapto groups with hydroxyls in these polyols actually reduced the functional group concentration due to dilution, i.e., lowered the total thiol plus hydroxyl number, but the benefit was high reactivity arising from primary $\mathrm{OH}$ groups. All polyols had around 3 primary $\mathrm{OH}$ groups and 2.7 secondary hydroxyls from the

original castor oil. Their structures were characterized by spectroscopic techniques and wet analysis. The polyols were used to prepare cast polyurethanes and rigid PU foams. Since the properties of polyurethanes depend on the structure of the isocyanates as well, three types of diisocyanate were used: aliphatic, cycloaliphatic and aromatic. Foams were made using polymeric MDI.

\section{EXPERIMENTAL}

\subsection{Materials}

Castor oil, having a hydroxyl number of $162 \mathrm{mg} \mathrm{KOH} / \mathrm{g}$ and iodine value of 85.5, was purchased from Alfa Aesar (Ward Hill, MA). The calculated number of double bonds per triglyceride was 3.12 and the molecular weight 928.

Mercaptanized castor oil (Polymercaptan PM 805-C) was kindly supplied by Chevron Phillips Chemical Company LP, Bartlesville, Oklahoma. It had a thiol equivalent weight of $352 \mathrm{~g} / \mathrm{eq}$, corresponding to $2.8 \mathrm{SH}$ groups/mol and a hydroxyl equivalent weight of 365 g/equivalent or $\mathrm{OH}$ number of $154 \mathrm{mg} \mathrm{KOH} / \mathrm{g}$. 
The total equivalent weight $(\mathrm{SH}+\mathrm{OH})$ of $181 \mathrm{~g} / \mathrm{eq}$ corresponds to total $\mathrm{OH}$ number $(\mathrm{SH}+\mathrm{OH})$ of $310 \mathrm{mg} \mathrm{KOH} / \mathrm{g}$. 2-Mercaptoethanol, 99.5\%, was also obtained from Chevron Phillips.

Allyl alcohol, 98\% was purchased from Alfa Aesar, 2-hydroxyethyl acrylate 97\% from Fisher Scientific and 2-hydroxy-2-methylpropiophenone 98\% (photoinitiator) from TCI America.

Silicone surfactant Tegostab ${ }^{\circledR}$ B 8404 was obtained from Evonik Industries, Inc. Niax ${ }^{\mathrm{TM}}$ A-1 catalyst bis (2-dimethylaminoethyl) ether was purchased from Momentive Performance Materials Inc. and DABCO ${ }^{\circledR} \mathrm{T}-12$ (dibutyltin dilaurate) from Air Products and Chemicals, Inc.

Rubinate $^{\circledR} 9225$ (uretonimine modified pure MDI with increased 2,4' isomer content and functionality 2.02, equivalent weight (EW) of 135) and polymeric MDI, Rubinate ${ }^{\circledR} \mathrm{M}$, having $31 \%$ NCO groups and functionality $2.7(\mathrm{EW}=135)$, were obtained from Huntsman Corporation; the latter was used only in foams. Aliphatic isocyanates m-xylylene diisocyanate (XDI) with EW=94 was purchased from Sigma-Aldrich Corp. (St. Louis, MO) and dicyclohexylmethane4,4'-diisocyanate (HMDI) having EW=131 (Desmodur ${ }^{\circledR} \mathrm{W}$ ) was purchased from Bayer Material Science (now Covestro LLC).

\subsection{Methods}

Hydroxyl numbers were determined by the $p$-toluenesulfonyl isocyanate method (ASTM 1899), polyol acid values were determined by titration with $0.1 \mathrm{~N} \mathrm{NaOH}$ in toluene-isopropanol mixture (ASTM D 4662). Viscosity was measured at $25^{\circ} \mathrm{C}$ on an AR $2000 \mathrm{EX}$ Rheometer (TA Instruments).

A size exclusion chromatography (SEC) system consisting of a Waters 515 pump (Waters Corp., Milford, MA), with a set of five Phenogel ${ }^{\mathrm{TM}}$ columns from Phenomenex ${ }^{\circledR}$ (Torrance, CA) covering a MW range of 100 to $5 \times 10^{5}$, were used for assessing molecular weight and MW distribution. Calibration was carried out using a range of triglycerides, diglycerides and fatty acid esters of similar structure. The eluent was tetrahydrofuran.

A Fourier transform infrared (FTIR) spectrophotometer (IRAffinity-1 from Shimadzu) was employed to analyze the structure of polyols and polyurethanes. NMR experiments were performed on a Bruker Avance DPX-300 spectrometer at $300 \mathrm{MHz}$ with a $5 \mathrm{~mm}$ broadband probe. Deuterated chloroform was used as solvent.

Tensile properties were measured on a Qtest-2 Tensile Tester from MTS ${ }^{\circledR}$, following protocols established by ASTM D882-97. DSC measurements were performed with differential scanning 
calorimeter model Q100 from TA Instruments (New Castle, DE, USA) in nitrogen (50 mL/min flow) at a heating rate of $10{ }^{\circ} \mathrm{C} / \mathrm{min}$ from $-80{ }^{\circ} \mathrm{C}$ to $200{ }^{\circ} \mathrm{C}$. Dynamic Mechanical Analysis (DMA) measurements were conducted using DMA 2980 from TA instruments (New Castle, DE) with a heating rate of $3{ }^{\circ} \mathrm{C} / \mathrm{min}$ from $-80{ }^{\circ} \mathrm{C}$ to $170{ }^{\circ} \mathrm{C}$ at $10 \mathrm{~Hz}$. Density of foams was determined according to ASTM D 1622. Compressive properties were measured on Q-Test 2 tensile machine $\left(\right.$ MTS $^{\circledR}$, USA) according to ASTM 1621. Close cell content of foams was measured by HumiPyc ${ }^{\mathrm{TM}}$ Volumetric \& RH Analyzer from InstruQuest, Inc. (Coconut Creek, FL), according to ASTM D 2856. The cellular structure and morphology of foams were observed via scanning electron microscopy (SEM) Phenom G2 Pro SEM (Netherlands). Before testing, the samples were gold-coated in a 108 Sputter Coater (Kurt J. Lesker Co.). Simulation of network formation and calculation of crosslinking density was carried out using the DryAdd-Pro+ program from Oxford Materials Ltd, UK.

\subsection{Polyol synthesis}

Three methods were used for preparation of castor oil polyols: two radical photochemical thiolene reactions and one nucleophilic Michael thiol-ene reaction.

\subsubsection{Method 1 (photochemical thiol-ene reaction)}

Castor oil and 2-mercaptoethanol (2ME) were reacted at room temperature for $3 \mathrm{~h}$ under irradiation of UV light $(365 \mathrm{~nm})$ in the presence of 2-hydroxy-2-methylpropiophenone as photoinitiator. The amount of photoinitiator was 1 weight $\%$ of the total reaction mass.

Molar ratio 2ME/double bond was 2/1. The excess of 2-mercaptoethanol was removed by vacuum distillation at $100-110^{\circ} \mathrm{C}$ and $2 \mathrm{~mm} \mathrm{Hg}$ (boiling point of $2 \mathrm{ME}$ at atmospheric pressure is $\left.157^{\circ} \mathrm{C}\right)$. This method was used to synthesize CO-2ME polyol.

\subsubsection{Method 2 (photochemical thiol-ene reaction of mercaptanized castor oil with allyl alcohol)}

Mercaptanized castor oil (MCO) was reacted with allyl alcohol (molar ratio allyl alcohol/SH groups= 2/1) during $3 \mathrm{~h}$ irradiation with UV light $(365 \mathrm{~nm})$ in the presence of the 
photoinitiator as in Method 1. Allyl alcohol having a low boiling point (b.p. $=96-98{ }^{\circ} \mathrm{C}$ ) was easily removed by vacuum distillation at $100-110{ }^{\circ} \mathrm{C}$. The product was the polyol designated as MCO-AA.

Photochemical reactions (Methods 1 and 2) were carried out in a $500 \mathrm{ml}$ photochemical reactor with a $450 \mathrm{~W}$ UV lamp, produced by Ace Glass. The reaction mass was mixed with a magnetic stirrer. The photochemical reactor was enclosed in a metal cabinet to avoid exposure to UV irradiation.

\subsubsection{Method 3 (nucleophilic Michael reaction)}

Nucleophilic Michael addition of the thiol groups of mercaptanized castor oil to the double bonds of 2-hydroxyethylacrylate was carried out in a $250 \mathrm{ml}$ round bottom flask equipped with stirrer, condenser, addition funnel, thermocouple and heating mantle with automatic regulation of temperature. The 2-hydroxyethyl acrylate (HEA) was added stepwise, under continuous stirring, from the addition funnel within one hour to mercaptanized castor oil (MCO). The molar ratio [HEA]/[SH] was $1 / 1$. The reaction was carried out at $40-50{ }^{\circ} \mathrm{C}$ in the presence of $0.5 \%$ of tetramethylguanidine as a catalyst. The mixture was maintained for 2 hours at $50{ }^{\circ} \mathrm{C}$ to complete the reaction. The polyol was designated as MCO-HEA.

\subsection{Preparation of cast PU and PU foams}

Cast PU sheets were prepared by mixing polyols with isocyanates at room temperature $(\mathrm{NCO} / \mathrm{OH}$ ratio $=1.02)$. In the case of low reactivity aliphatic isocyanates (XDI and HMDI) the mixture was heated at $70{ }^{\circ} \mathrm{C}$ under vacuum $(20-30 \mathrm{mmHg})$, during 30 minutes. A homogeneous and transparent mixture of relatively low viscosity was poured to a stainless steel mold, which was heated in an oven at $110{ }^{\circ} \mathrm{C}$, for around 24 hours. The samples were $1.75 \mathrm{~mm}$ x100 $\mathrm{mm} \times$ $100 \mathrm{~mm}$ sheets. Test specimens for mechanical testing were cut from the sheets as $100 \mathrm{~mm}$ long and $8 \mathrm{~mm}$ wide strips.

With aromatic isocyanate (MDI) the reaction rate with polyols was very high and only two samples could be cast, those with CO-2ME and MCO-AA. Gel time with the polyol MCOHEA was about one minute. High reactivity may have arisen from the presence of the residual N,N,N'N'-tetramethylguanidine catalyst used for Michael reaction. 


\subsection{Preparation of rigid polyurethane foams}

A polyol component was prepared by mixing $20 \mathrm{~g}$ of polyol with silicone surfactant, amine and tin catalysts, and water (see Table 2). Rigid PU foams were made by vigorously mixing the polyol component with polymeric MDI (Rubinate ${ }^{\circledR} \mathrm{M}$ ), at an isocyanate index of 105 for 10 seconds in a polystyrene cup at 3000 rotations/minute.

The foams were characterized after one week stabilization at room temperature by measuring apparent density, compression strength at $10 \%$ strain, average cell size and closed cell content.

\section{RESULTS AND DISCUSSION}

\subsection{Polyols}

Thiol-ene reaction is the anti-Markovnikov addition of thiol groups (-SH) to double bonds in the presence of UV light, with formation of thioether bonds (Scheme 2) [19-25].

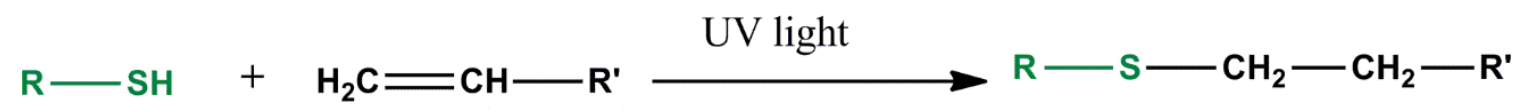

Scheme 2. General thiol-ene reaction.

The photochemical thiol-ene reaction was carried out in the presence of a 2-hydroxy-2methylpropiophenone photoinitiator. The photoinitiator is decomposed by UV light to two free radicals, which by transfer with thiol groups generate thiyl radicals. The formed thiyl radicals are added (anti-Markovnikov addition) to double bonds [19-25]. The newly formed radical again enters the transfer reaction with thiol groups generating a new thiyl radical, which continues the radical chain reaction.

Addition of 2-mercaptoethanol to double bonds of castor oil gave a CO-2ME polyol with hydroxyethyl groups linked to the fatty acid chains via thioether sulfur atoms (Scheme 3). The position of the addition of the mercapto group is pictured as the 10-carbon for convenience, but addition to carbon 9 is equally probable. 


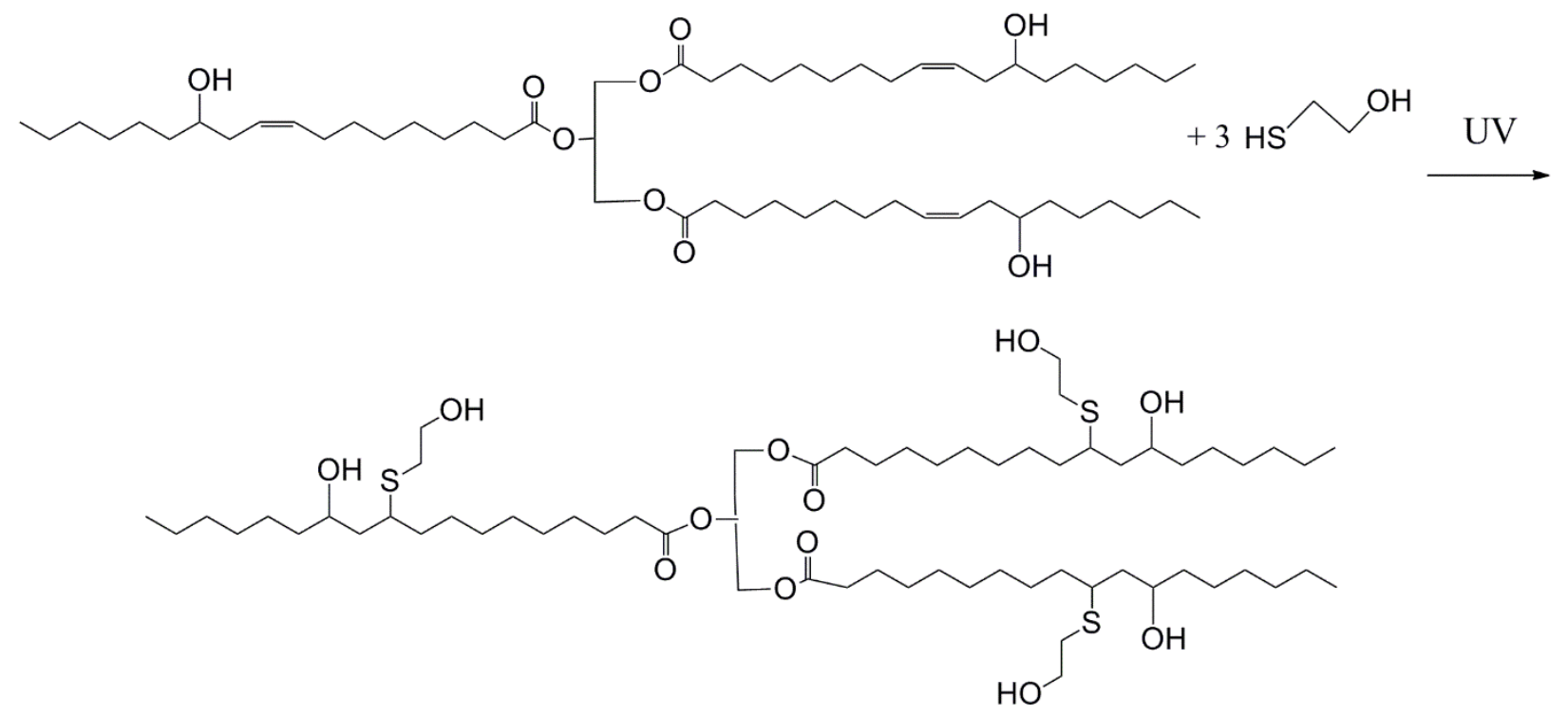

Scheme 3. Thiol-ene addition of 2-mercaptoethanol (2ME) to double bonds of castor oil (CO).

The SEC curve for this polyol (CO-2ME), Fig. 1, shows virtually a single peak with a small dimer peak at 30 min elution time, indicating that a very small amount of side reaction took place. The shift of the main peak to lower elution volumes (times) relative to castor oil is due to the increased molecular weight. It should be emphasized that the addition of $2 \mathrm{ME}$ to $\mathrm{CO}$ does not give a new distinct peak but causes a shift to lower retention time. Presumably joining two triglyceride thiyl radicals produces a distinct peak at about $30 \mathrm{~min}$ that we will refer to as dimer.

We have observed that fatty acids with one double bond (oleic, ricinoleic) gave higher yields in photochemical thiol-ene reactions with mercaptans than did fatty acids with two or three double bonds. Similar observations were made by Bantchev et al. [22]. This fact is explained by the presence of bisallylic positions in the latter, which are strong transfer agents in radical reactions. The expected hydroxyl number $(\mathrm{OH} \#)$ is $278 \mathrm{mg} \mathrm{KOH} / \mathrm{g}$ for complete reaction of double bonds of castor oil having an iodine value (IV) of 85.5 (3.12 double bonds/mol). However, the experimental value, Table 1, for CO-2ME polyol prepared by this method was $7.74 \mathrm{mg} \mathrm{KOH/g}$, higher than theoretical, probably due to the presence of traces of 2-mercaptoethanol or its dimer. The yield of the polyol was close to theoretical. Thus, the functionality of this polyol should be $2.7+3.1=5.8$. 


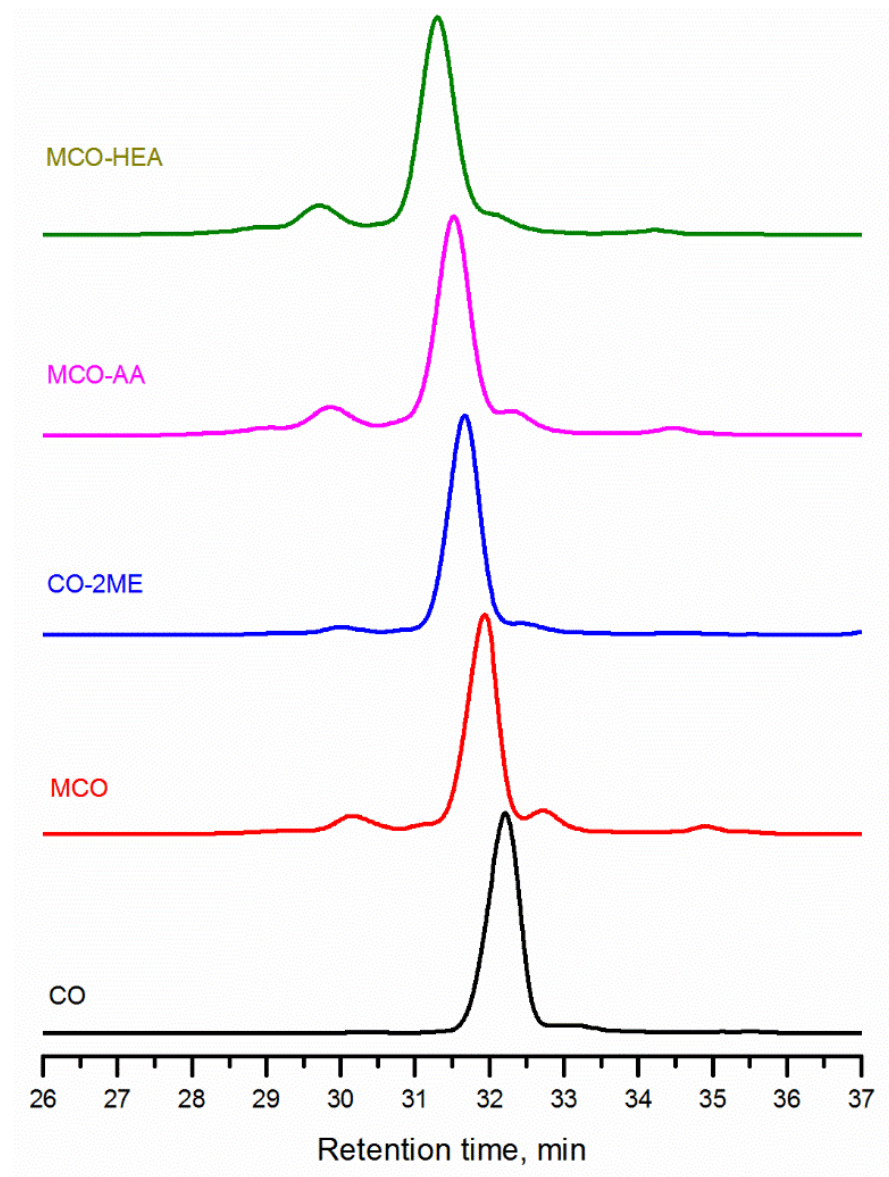

Fig.1. Overlay of SEC chromatograms of polyols CO-2ME, MCO-AA and MCO-HEA, together with castor oil (CO) and mercaptanized castor oil (MCO).

The second polyol designated as MCO-AA, was produced from mercaptanized castor oil (MCO) and allyl alcohol using method 2. Mercaptanized castor oil (MCO) has both thiol and hydroxyl groups. Secondary thiol groups of low reactivity, when reacted with allyl alcohol, produced reactive terminal hydroxyl groups as shown in Scheme 4. 

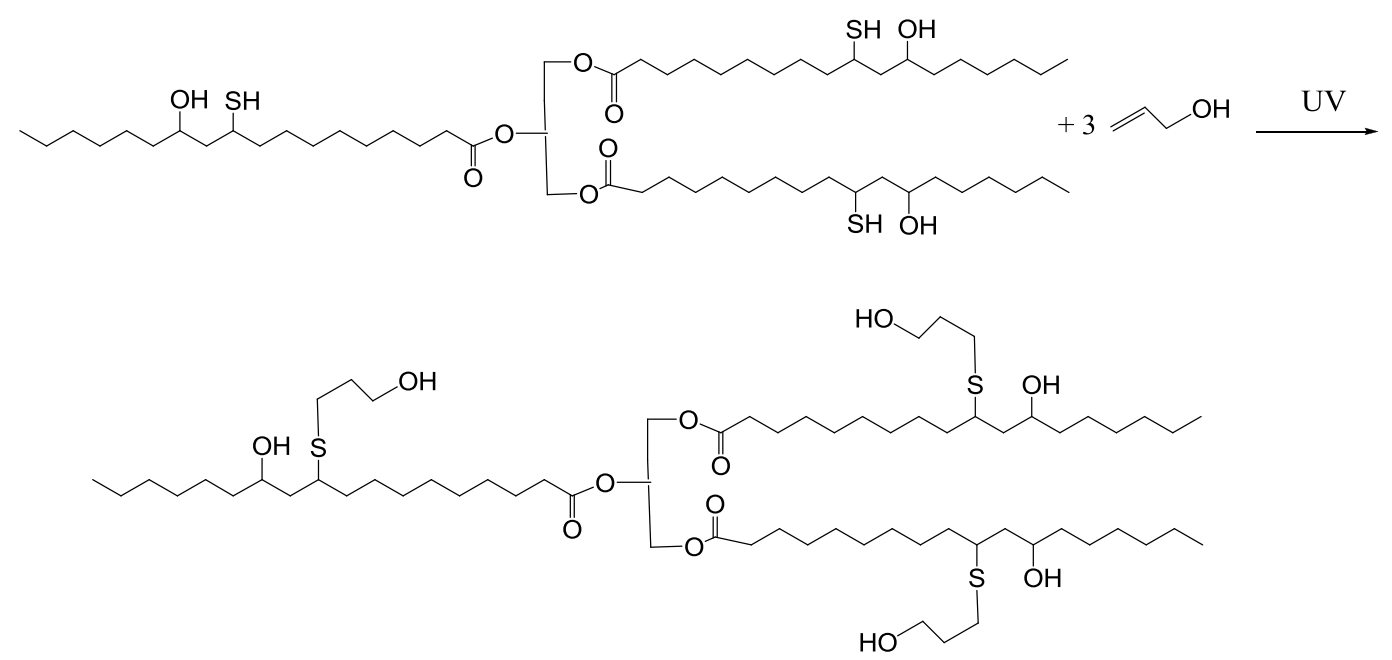

Scheme 4. Synthesis of a castor oil polyol (MCO-AA) by thiol-ene reaction of mercaptanized castor oil (MCO) with allyl alcohol (AA).

Since the mercaptanized castor oil had on average 2.8 thiol groups, the number of $\mathrm{OH}$ groups per mol of a polyol at complete addition of thiol groups to allyl alcohol should be $2.8+2.7=5.5$, corresponding to a theoretical hydroxyl number of $268 \mathrm{mg} \mathrm{KOH} / \mathrm{g}$. The experimental value for the hydroxyl number was $258 \mathrm{mg} \mathrm{KOH} / \mathrm{g}$, i.e., the reaction yield was $96.3 \%$. The SEC curve for this polyol displayed in Figure 1 shows the main peak with retention time at 31.8 min, slightly shifted from the MCO main peak at 32 min as a consequence of increased molecular weight. Weak peaks at 32.8 (diglyceride) and 30 min (triglyceride dimer) in the polyol remain from the starting material, MCO. The weight \% of dimer may increase slightly and shift to a slightly lower retention time because of the addition of reactants to the triglyceride dimer.

Michael thiol-ene reaction is catalyzed by bases such as phosphines or tertiary amines. The catalyst transforms the thiol group to mercaptide anion, a strong nucleophile, which is added to the activated double bonds. The double bond in 2-hydroxyethylacrylate is activated by the electron-withdrawing effect of the acrylic ester carbonyl group. Other electron-withdrawing substituents could be carbonyl, sulfoxide, sulfone, nitro groups and others [36]. The mechanism of the Michael nucleophilic thiol-ene reaction is presented in Scheme 5 [36,37]. 

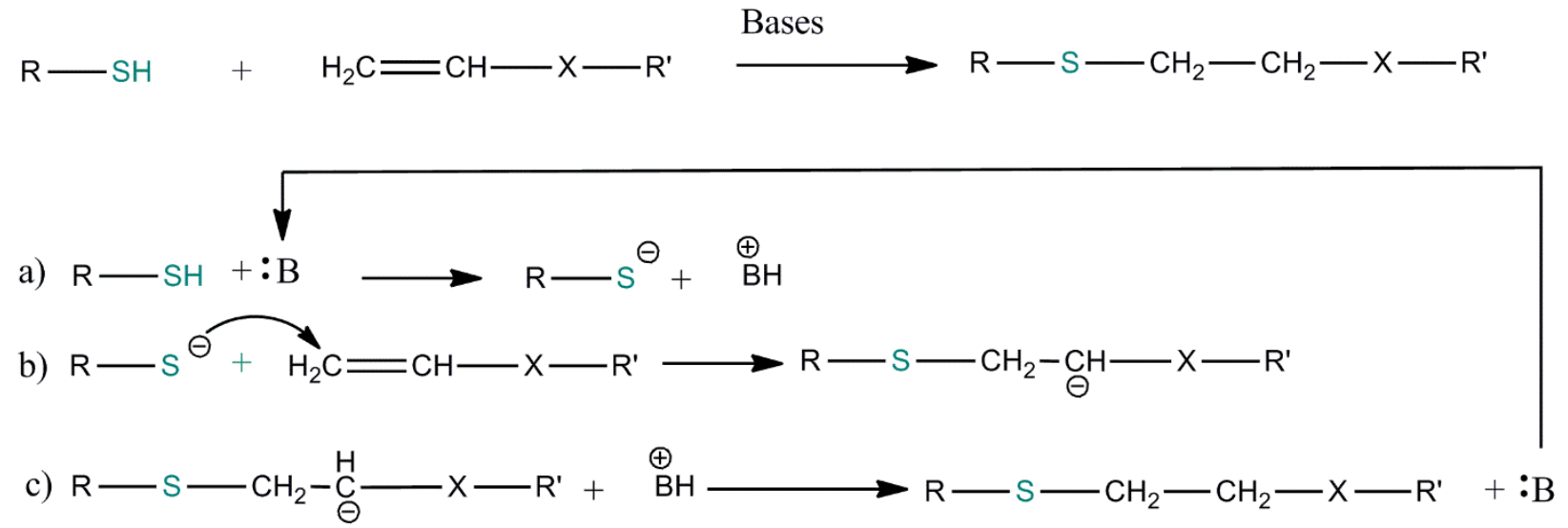

Scheme 5. Michael addition of mercaptans to double bonds.

The catalyst, generally a base, transforms the thiol group to mercaptide anion, a strong nucleophile, which reacts very efficiently with the activated double bonds. The catalyst used for this reaction was N,N,N'N'-tetramethylguanidine, an organic superbase, which efficiently catalyzes Michael thiol-ene reactions at lower temperatures. The reaction of HEA with mercaptanized castor oil is shown in Scheme 6. Considering the thiol-functionality of $2.8 \mathrm{SH}$ groups/mol and hydroxyl functionality of $2.7 \mathrm{OH}$ groups/mol, the theoretical functionality of the polyol should be 5.5 and $\mathrm{OH \#}$ at complete reaction of thiol groups with HEA should be around $235 \mathrm{mg} \mathrm{KOH} / \mathrm{g}$. The hydroxyl number of polyol MCO-HEA of $218 \mathrm{mg} \mathrm{KOH} / \mathrm{g}$ represents a yield of thiol-ene reaction of $92.6 \%$ and functionality 5.1. Lower $\mathrm{OH}$ number and reduced functionality are consequences of the formation of a small amount of polyol dimers with elution time at $29.8 \mathrm{~min}$, as observed by SEC.

The SEC curve of the MCO-HEA polyol shown in Fig. 1, has the main peak at 32 min with a small amount of a higher molecular weight components below $30 \mathrm{~min}$ and small diglyceride shoulder at $32.2 \mathrm{~min}$, which existed in the starting MCO. Traces of HEA were observed at 40 min elution time. Thus, side reactions took place only to a small extent. 

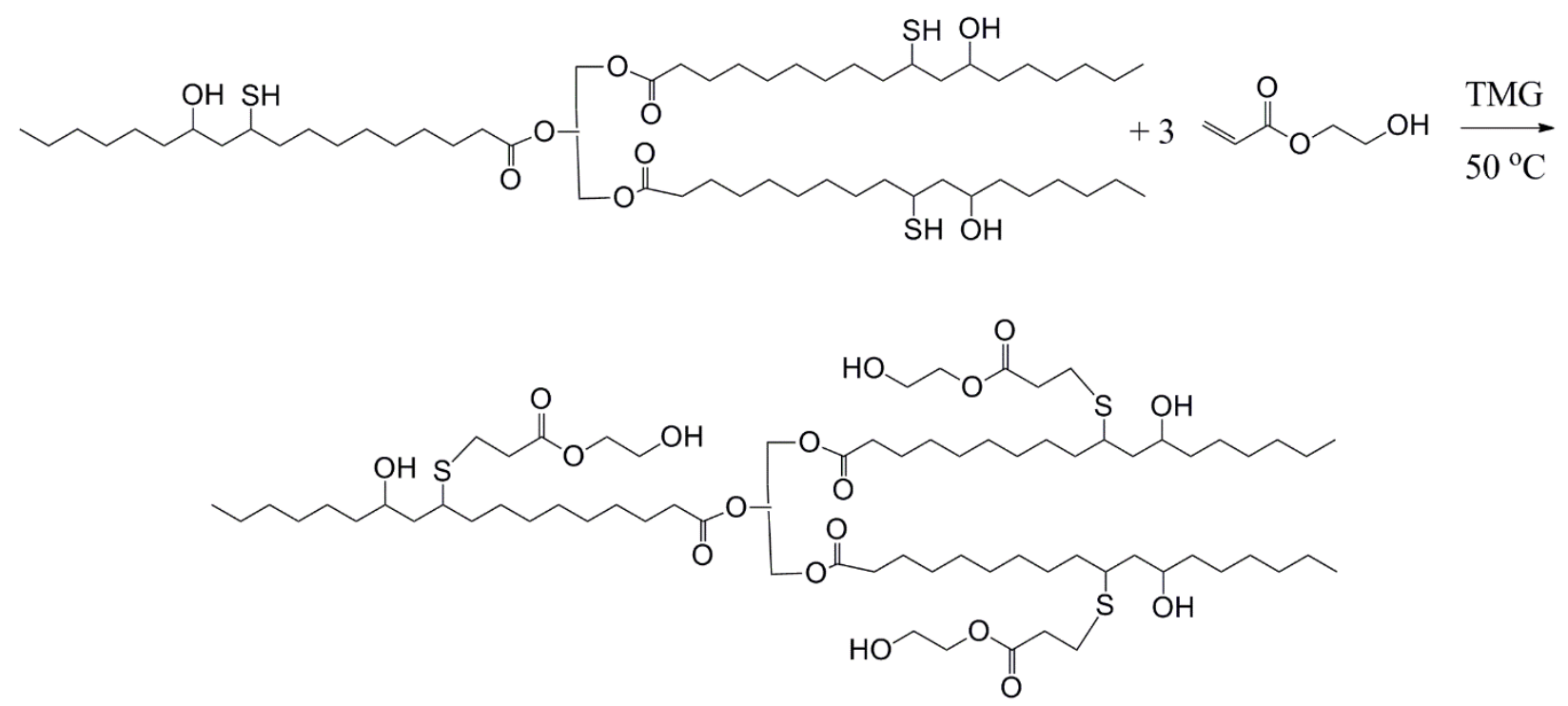

Scheme 6. Synthesis of MCO-HEA polyol by nucleophilic Michel reaction of mercaptanized castor oil (MCO) with 2-hydroxyethyl acrylate (HEA).

Fig. 2 displays the FT-IR spectra of the castor oil polyols prepared by thiol-ene reactions. The spectra are relatively similar. The broad absorption band at around $3400 \mathrm{~cm}^{-1}$ is characteristic for hydroxyl groups and the peak at $1740-1750 \mathrm{~cm}^{-1}$ is assigned to carbonyl groups from ester bonds in the triglyceride, and acrylate in the case of MCO-HEA polyols. Polyols CO2ME and MCO-AA have only one type of carbonyl groups from the triglyceride ester bonds. No specific absorptions for thiol or sulfur-carbon bonds were observed.

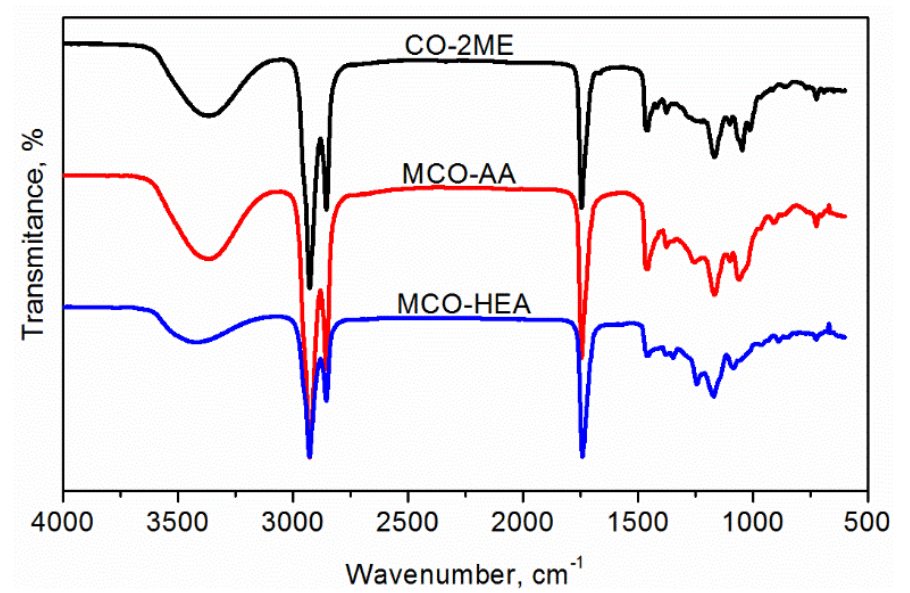

Fig. 2. FT-IR spectra of CO-2ME, MCO-AA and MCO-HEA. 
Polyols were transparent light brown (CO-2ME) or light yellow liquids (MCO-AA and MCOHEA). Table 1 shows characteristics of the three polyols. The hydroxyl numbers of the polyols were 218-286 $\mathrm{mg} \mathrm{KOH} / \mathrm{g}$, corresponding to 5.1-5.8 $\mathrm{OH}$ groups/mol. The viscosity of these polyols is higher than that of comparable petrochemical polyols but is still in the range of 11-19 $\mathrm{Pa} \cdot \mathrm{s}$ at $25{ }^{\circ} \mathrm{C}$, acceptable for the preparation of rigid polyurethane foams by conventional methods.

Table 1. Characteristics of castor polyols synthesized by thiol-ene reactions

\begin{tabular}{lllccccc}
\hline Polyol & OH\#, & Acid value, & Viscosity, & Mn* & Mn** & f \\
& $\mathrm{mg} \mathrm{KOH} / \mathrm{g}$ & $\mathrm{mg} \mathrm{KOH} / \mathrm{g}$ & $\mathrm{Pa} \cdot \mathrm{s} @ 25^{\circ} \mathrm{C}$ & & & \\
\hline $\mathrm{CO}-2 \mathrm{ME}$ & 286 & 0.98 & 15.5 & 1220 & 1144 & 5.8 \\
\hline MCO-AA & 258 & 2.74 & 18.6 & 1850 & 1184 & 5.5 \\
\hline MCO-HEA & 218 & 4.94 & 11.8 & 1450 & 1300 & 5.1 \\
\hline
\end{tabular}

*Molecular weights determined by SEC are approximate values. **Calculated from the structure.

The SEC chromatograms reflected the high yield of thiol-ene reactions and the presence only of minor amounts of low molecular weight compounds. Viscosity of polyols is affected by their hydroxyl numbers and molecular weights. Higher SEC molecular weights than calculated for MCO-AA and MCO-HEA were due to the presence of dimers which partly originated from the starting $\mathrm{MCO}$. Total functionality $(\mathrm{SH}+\mathrm{OH})$ in the MCO-AA polyol should not change (5.5) with conversion in the thiol-ene reaction, because each $\mathrm{SH}$ group should produce a hydroxyl group, unless there are side reactions. However, unreacted SH groups are slower to react with isocyanates in the absence of catalysts and may affect the conversion rate during polyurethane network formation.

Proton NMR spectra of the three polyols are shown in Figures 3-5. 


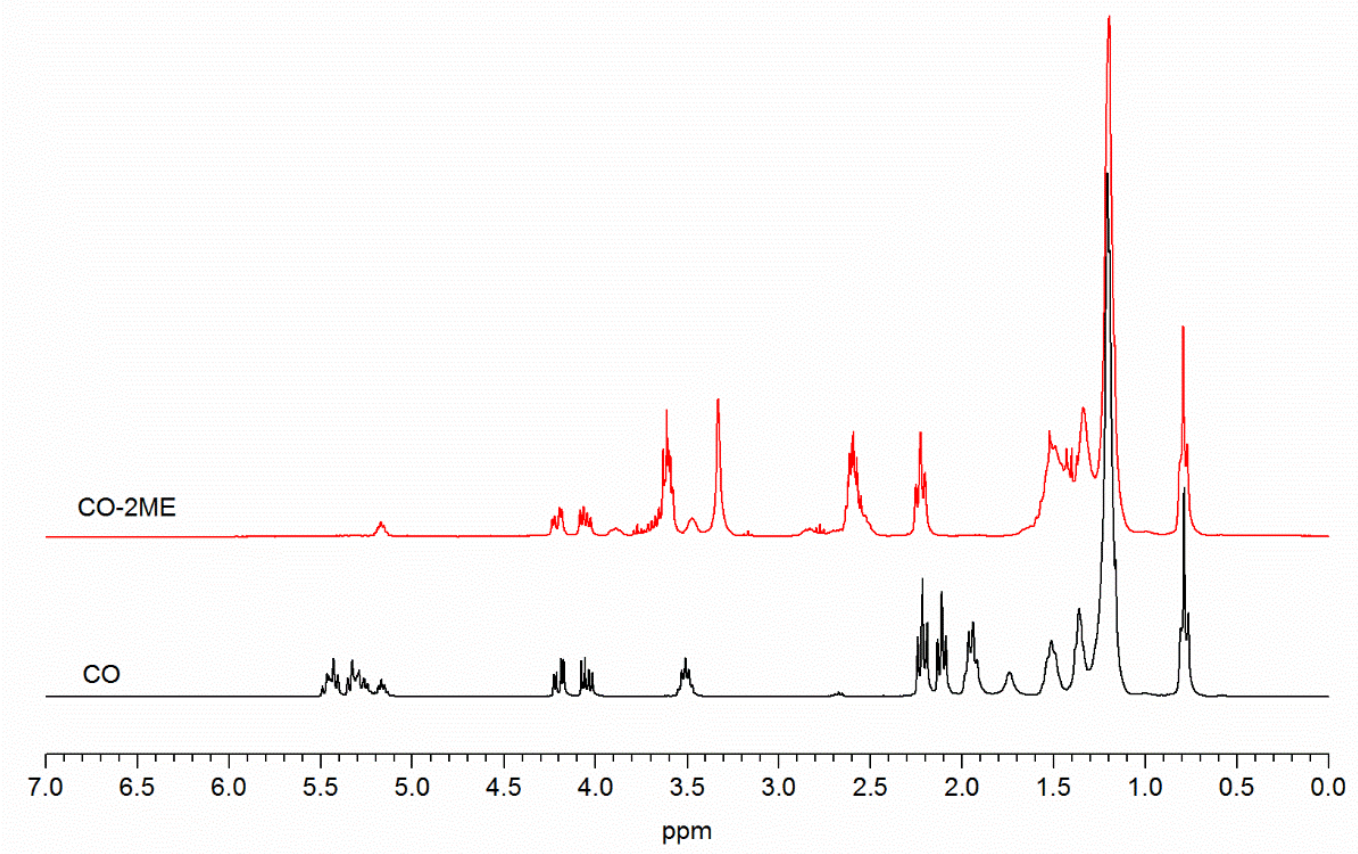

Fig. 3. ${ }^{1} \mathrm{H}$ NMR spectra overlay of castor oil $(\mathrm{CO})$ and polyol prepared by thiol-ene addition of 2-mercaptoethanol to castor oil (CO-2ME).

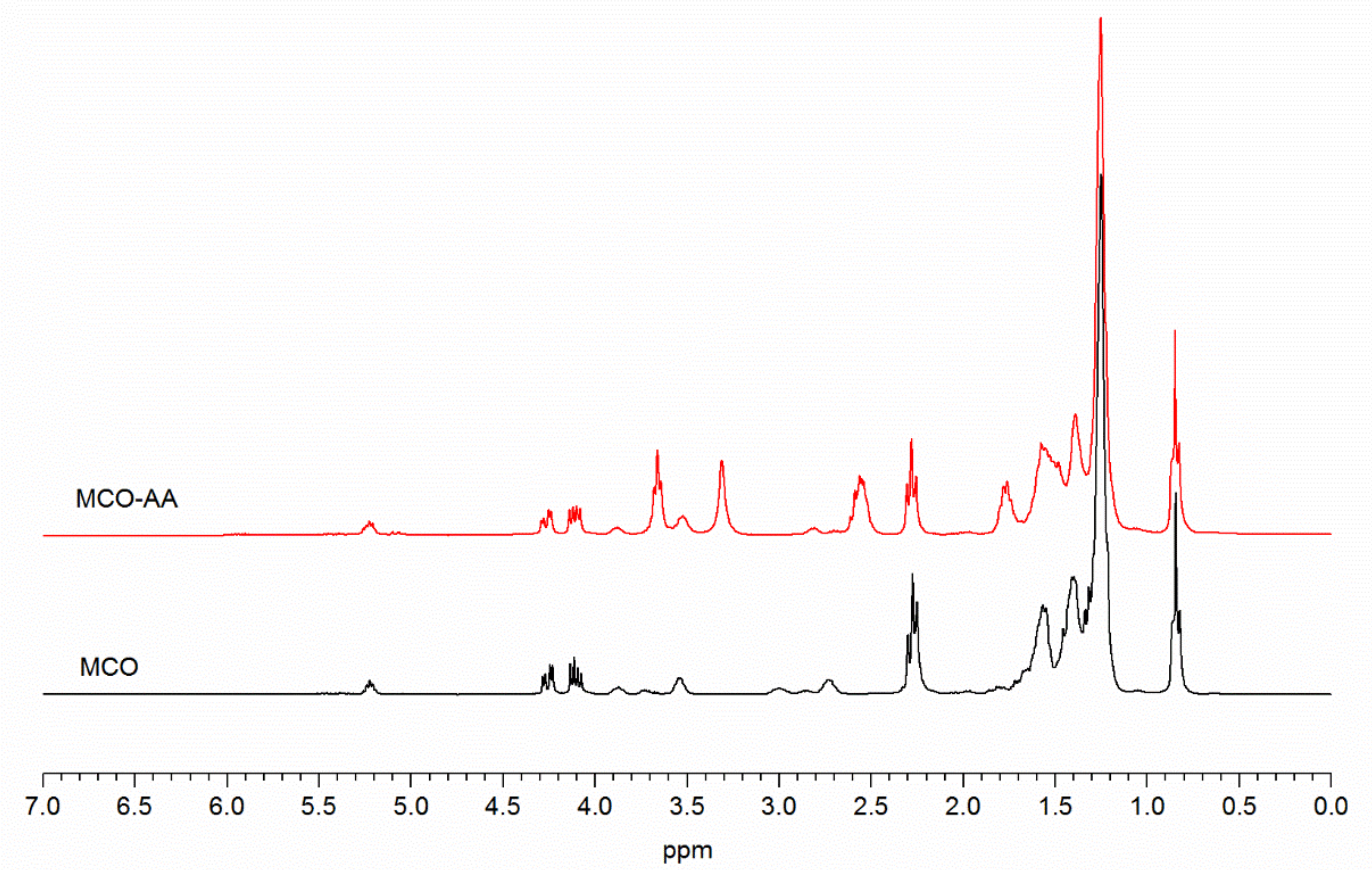

Fig. 4. ${ }^{1} \mathrm{H}$ NMR spectra overlay of mercaptanized castor oil (MCO) and polyol based on mercaptanized castor oil and allyl alcohol (MCO-AA). 


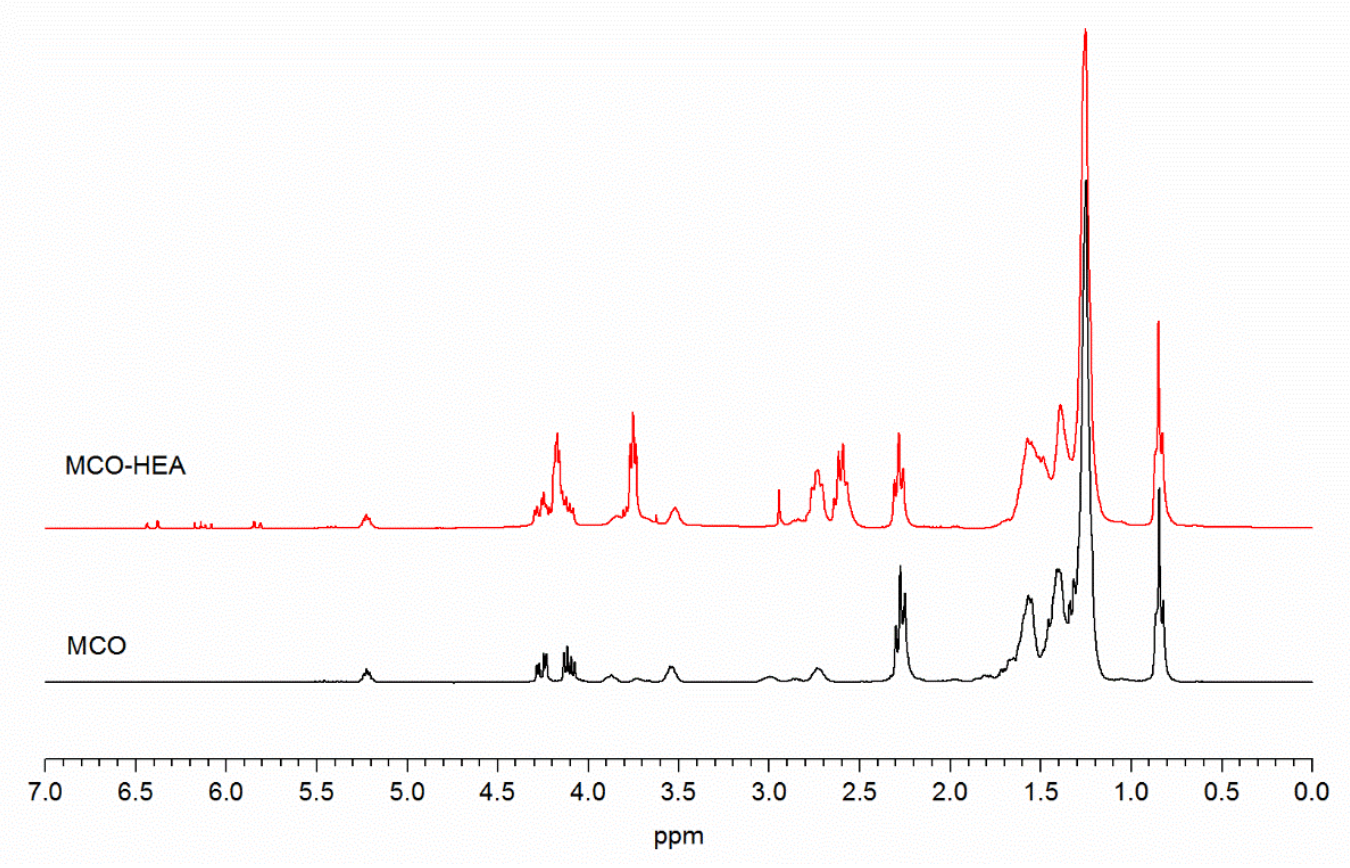

Fig. 5. ${ }^{1} \mathrm{H}$ NMR spectra overlay of mercaptanized castor oil (MCO) and polyol based on mercaptanized castor oil and 2-hyroxyethyl acrylate (MCO-HEA).

${ }^{1} \mathrm{H}$ NMR of castor oil (CO) shows the presence of terminal methyl group at $0.85 \mathrm{ppm}$; methylene group ranges from 1.27 to $1.52 \mathrm{ppm}$; methylene group adjacent to carbonyl of triglyceride ester bond at 2.22 ppm; glycerol methylene protons as doublet of multiplet centered at $4.2 \mathrm{ppm}$; and glycerol methine proton as multiplet at $5.23 \mathrm{ppm}$. The characteristic thioether peak appears in the ${ }^{1} \mathrm{H}$ NMR spectrum of CO-2ME polyol at $2.59 \mathrm{ppm}$ (Fig. 3). Multiplet centered at $5.37 \mathrm{ppm}$ corresponds to olefinic protons from castor oil which is absent in ${ }^{1} \mathrm{H}$ NMR spectrum of CO$2 \mathrm{ME}$, indicates that the double bonds reacted. Similarly, thioether protons at $2.49 \mathrm{ppm}$ and at 2.53 ppm are present in MCO-AA (Fig. 4) and in MCO-HEA (Fig. 5) respectively. Overlapping and discrete peaks from residual monomers are also observed in the spectra of each polyol. Peaks centered at around $5.9 \mathrm{ppm}$ in the MCO-AA spectrum correspond to residual AA. Likewise, peaks ranging from $5.7-6.3 \mathrm{ppm}$ in the MCO-HEA spectrum correspond to residual HEA. 


\subsection{Cast polyurethanes}

Three diisocyanates, modified MDI (Rubinate ${ }^{\circledR}$ 9225), m-xylylenediisocyanate (XDI) and dicyclohexylmethane-4,4'-diisocyanate (HMDI), were used to prepare cast polyurethanes with three polyols. Mixing the polyols with the modified MDI was difficult because of the unexpectedly high reactivity with polyols, even at room temperature, due to the high functionality and high content of primary hydroxyls (around 50-55\%). Polyurethanes with MDI could be made with polyols CO-2ME and MCO-AA but not with MCO-HEA possibly because of the catalytic effect of residual tetramethylguanidine from the synthesis. The system MCOHEA/MDI turned to a solid gel in less than a minute. Cast PU's were easily made with XDI and HMDI because of their much lower reactivity. These two diisocyanates allowed processing times of around 30 minutes at $70{ }^{\circ} \mathrm{C}$. FT-IR spectra showed that not all of the polyurethanes were completely cured. All properties were measured on samples cured at $110{ }^{\circ} \mathrm{C}$. Only samples for DSC and FT-IR were cured also at $150{ }^{\circ} \mathrm{C}$ to observe if there was a shift in the $\mathrm{T}_{\mathrm{g}}$ and a reduction of residual isocyanate in the cured samples.

FT-IR spectra of cast polyurethanes revealed the isocyanate peak at $2260 \mathrm{~cm}^{-1}$, which disappeared after additional heating at $150{ }^{\circ} \mathrm{C}$ for 24 h. Fig. 6 shows FTIR spectra of CO2ME/HMDI polyurethane before and after heating at $150{ }^{\circ} \mathrm{C}$ (other samples were cured only at $110^{\circ} \mathrm{C}$ ). The absence of an NCO peak in MCO-HEA/XDI after heating only at $110{ }^{\circ} \mathrm{C}$ suggests that the curing rate in this sample was higher as a consequence of the catalytic effect of residual tetramethylguanidine from the polyol synthesis. Characteristic bands for these polyurethanes are $\mathrm{N}-\mathrm{H}$ stretching at $3300 \mathrm{~cm}^{-1}$ and carbonyl peaks from oil ester and urethane bonds at around $1710 \mathrm{~cm}^{-1}$. 


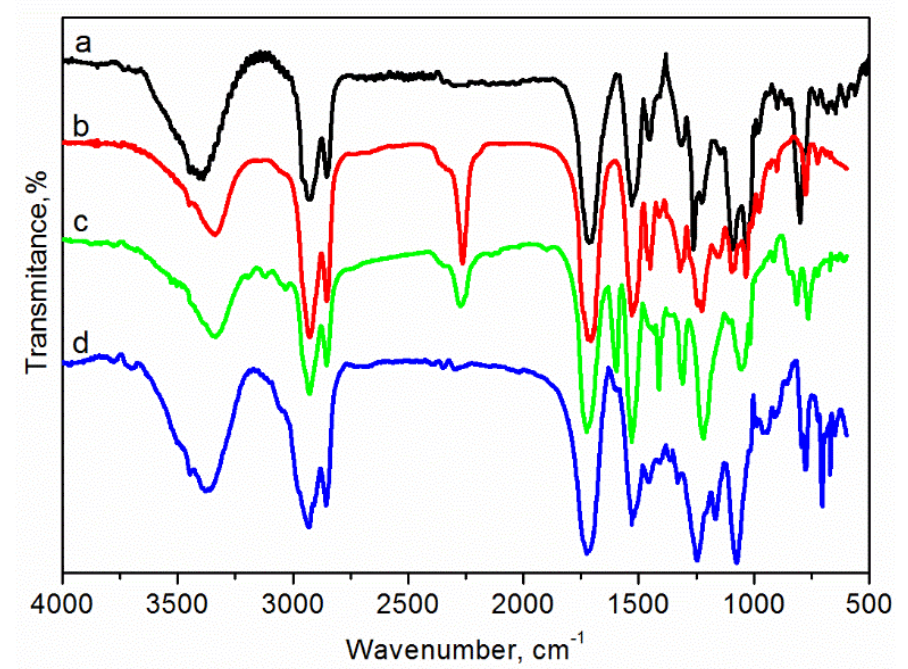

Fig. 6. FT-IR of four polyurethanes cured with MDI, XDI and HMDI. (a) CO-2ME/HMDI polyurethane after heating at $150{ }^{\circ} \mathrm{C}$, (b) CO-2ME/HMDI, (c) MCO-AA/MDI, and (d) MCOHEA/XDI.

The DSC curves of nine samples displayed in Fig. 7 show no crystallinity, indicating that all samples were amorphous solids with glass transition temperatures indicated in Table 2 . All three samples with aliphatic XDI displayed $\mathrm{T}_{\mathrm{g}}$ values below room temperature in spite of the high functionality of the polyols. As FT-IR shows, the samples were not completely cured. After additional heating at $150{ }^{\circ} \mathrm{C}$ for $24 \mathrm{~h}$, the $\mathrm{T}_{\mathrm{g}}$ values of all samples increased by $2-20{ }^{\circ} \mathrm{C}$. Thus a temperature of $150{ }^{\circ} \mathrm{C}$ is required for complete curing. 


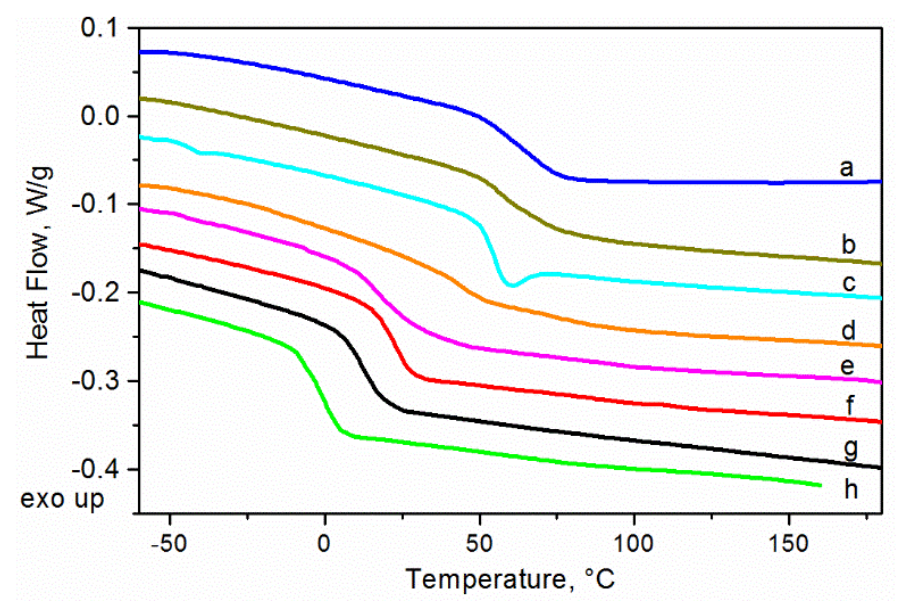

Fig. 7. DSC curves for polyurethanes: (a) CO-2ME/MDI, (b) MCO-AA/MDI, (c) MCOAA/HMDI, (d) CO-2ME/MDI, (e) MCO-HEA/HMDI, (f) MCO-AA/XDI, (g) CO-2ME/XDI, (h) MCO-HEA/XDI.

Dynamic mechanical analysis (DMA) of eight samples presented in Fig. 8 shows glassy region with storage modulus between 1 and $2 \mathrm{GPa}$ and variations within these values depending on the structure. Although networks are densely crosslinked, they are plasticized by dangling chains, which lower their rigidity. Only three samples showed a rubbery modulus on storage modulus curves; the others broke above $\mathrm{T}_{\mathrm{g}}$. Lower glassy storage moduli were found in XDI cured polyurethanes, which also showed lower $\mathrm{T}_{\mathrm{g}}$ values. Glass transition temperatures were taken from the maxima of loss modulus curves because these give values closer to those from DSC. However, glass transition was more clearly observed on tan $\delta$ - temperature diagrams, Fig. 9. Several samples displayed clear $\beta$-transitions in the $30-48{ }^{\circ} \mathrm{C}$ range, except the MCO-AA/MDI system where it was at $11^{\circ} \mathrm{C}$. The origin of $\beta$ - transitions is not clear. 


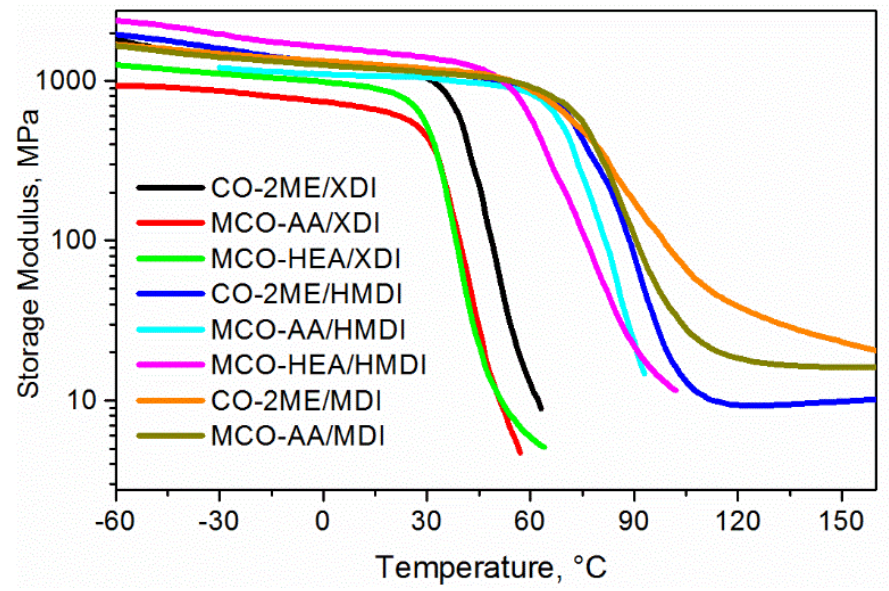

Fig. 8. Storage moduli of polyurethanes from highly functional polyols.

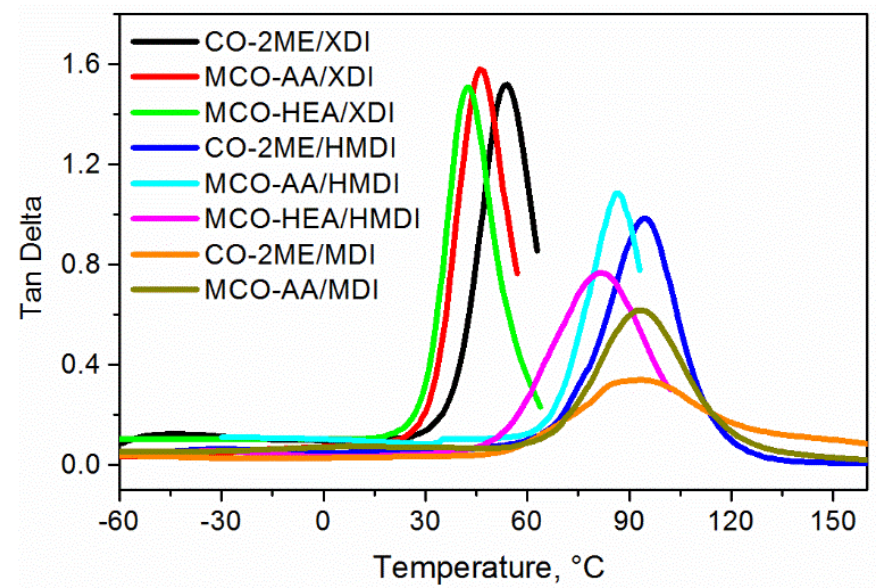

Fig. 9. Tan delta curves of polyurethanes from highly functional polyols.

Crosslink density calculated from the structure of components using Monte Carlo simulation gave for all systems cured with HMDI values for molecular weight of network chains, $\mathrm{M}_{\mathrm{c}}$, of around 700. This value is close to $\mathbf{M}_{\mathrm{c}}$ for networks with all isocyanates. The program assumes that hydroxyl groups are terminal. However, since the ricinoleic $\mathrm{OH}$ group is on the $12^{\text {th }}$ carbon, effective crosslink density would be higher. Dangling chains of 6 carbon atoms act as plasticizers. Cast polyurethanes with XDI were rubbers at room temperature but harder than a castor oil reference PU. Polyurethanes with HMDI and modified MDI were amorphous glasses with glass transition temperatures about 15-30 degrees above room temperature. Weight gain after swelling for $48 \mathrm{~h}$ in toluene was below $2 \%$, which suggests relatively high crosslink 
density. Sol fraction, which reflects the extent of the reaction, indicates that samples with MDI, with 7.7 and $5 \%$ of extractables, were not completely cured.

\subsubsection{Mechanical properties}

Mechanical properties of the cast polyurethanes cured at $110{ }^{\circ} \mathrm{C}$ for $24 \mathrm{~h}$ are shown in Table 2.

In spite of the high functionality of the polyols, the overall rubbery nature of XDI-cured polyurethanes led to relatively low tensile strength, hardness and modulus and to high elongations. HMDI (hydrogenated MDI) gives polyurethanes with good tensile strength, elongations below $10 \%$ and moduli between 244 and $740 \mathrm{MPa}$, similar to polyethylene. CO2ME and MCO-AA polyols cured with MDI and MCO-AA cured with HMDI gave high modulus in the GPa range, typical for glassy polymers. A reference cast polyurethane from unmodified castor oil and MDI, had a $\mathrm{T}_{\mathrm{g}}$ at around $5{ }^{\circ} \mathrm{C}$, lower hardness, lower tensile strength and higher elongation than the cast polyurethanes from high functionality castor oil polyols CO2ME and MCO-AA with the same isocyanate. Polyurethanes from high functionality polyol display better mechanical properties that casting polyurethanes compounds from castor oil used for electrical insulation [38].

Table 2. Properties of cast polyurethanes from high functionality castor oil polyols

\begin{tabular}{|c|c|c|c|c|c|c|c|}
\hline $\begin{array}{l}\text { Isocyanate / } \\
\text { Polyol }\end{array}$ & $\begin{array}{c}\mathbf{T}_{\mathrm{g}}^{(\mathbf{1})} \\
(\mathbf{D S C}) \\
\left({ }^{\circ} \mathrm{C}\right)\end{array}$ & $\begin{array}{l}\mathbf{T}_{\mathrm{g}}^{(2)} \\
(\mathbf{D M A}) \\
\left({ }^{\circ} \mathbf{C}\right)\end{array}$ & $\begin{array}{l}\text { Tensile } \\
\text { Strength } \\
\text { (MPa) }\end{array}$ & $\begin{array}{l}\text { Elonga- } \\
\text { tion (\%) }\end{array}$ & $\begin{array}{l}\text { Modulus }^{(3)} \\
\text { (MPa) }\end{array}$ & $\begin{array}{l}\text { Hardness } \\
\text { (Shore D) }\end{array}$ & $\begin{array}{l}\text { Soluble } \\
\text { fraction } \\
(\%)\end{array}$ \\
\hline \multicolumn{8}{|l|}{$X D I$} \\
\hline CO-2ME & $12(24)$ & $40(-48)$ & 2.5 & 112 & 6.2 & 31 & 0.2 \\
\hline MCO-AA & $20(22)$ & 35 & 3.9 & 84 & 17 & 38 & 0.4 \\
\hline MCO-HEA & $13(18)$ & 33 & 4.7 & 17 & 161 & 25 & 0.2 \\
\hline \multicolumn{8}{|l|}{$H M D I$} \\
\hline CO-2ME & $38(63)$ & $74(-31)$ & 36.4 & 5 & $500(503)$ & 60 & 4.4 \\
\hline MCO-AA & $46(54)$ & 71 & 35.3 & 9 & $743(1042)$ & 65 & 2.8 \\
\hline MCO-HEA & 16(19) & 60 & 15.3 & 4 & $244(448)$ & 50 & 1.9 \\
\hline
\end{tabular}




\begin{tabular}{llllllll} 
CO-2ME & $54(73)$ & 72 & 43.9 & 6 & $1169(1035)$ & 58 & 7.7 \\
MCO-AA & $28(41)$ & $77(+11)$ & 35.6 & 8 & $875(1034)$ & 66 & 5.0 \\
\hline Castor oil & 5 & & 3.2 & 137 & 4 & 16 & 0.35
\end{tabular}

\footnotetext{
${ }^{1}$ Values in parentheses after heating at $150{ }^{\circ} \mathrm{C} .{ }^{2}$ Values in parentheses refer to $\beta$-transition temp.

${ }^{3}$ Young's Modulus, with flexural modulus in parentheses.
}

Three polyols made by different methods had rather similar structures and molecular weights but different functionalities as a consequence of the reaction conditions. MCO-HEA polyol has additional ester groups which may increase chain interaction, but it has the lowest $\mathrm{OH}$ number, partly due to the higher molecular weight of HEA (dilution effect) but also due to potential side reactions and incomplete conversion. Higher $\mathrm{OH}$ numbers require higher isocyanate content, which increases the rigidity of the products when using aromatic diisocyanates. MCO-HEA gave consistently lower $T_{g}$, tensile strength, modulus and elongation with HMDI and MDI. These tests have confirmed that aliphatic isocyanates give softer polyurethanes than cycloaliphatic and aromatic isocyanates.

\subsubsection{Thermal stability of polyurethanes}

Sulfur-carbon bonds are less thermally stable than C-C bonds. However, the polyurethanes, did not show appreciable weight loss below $220{ }^{\circ} \mathrm{C}$ as measured by thermogravimetric analysis (Fig.10), which is considered the onset temperature for the degradation of the urethane bond. Primary hydroxyls give more stable urethanes than secondary hydroxyls coming from ricinoleic acid. In theory, aliphatic isocyanates with aliphatic polyols give more stable urethane bonds than aromatic isocyanates with aliphatic polyols. The knee on the curves was at about $300{ }^{\circ} \mathrm{C}$ but the most thermally stable were, in order of stability, MCOHEA/HMDI > MCO-AA/HMDI > CO-2ME/HMDI and the least stable were CO-2ME/XDI and MCO-HEA/XDI. The highest thermal stability was obtained with cycloaliphatic HMDI and the lowest, with MDI. The comparison was made by observing temperature at $5 \%$ weight loss. Weight loss at $600{ }^{\circ} \mathrm{C}$ was complete except the samples made with aromatic diisocyanate. 


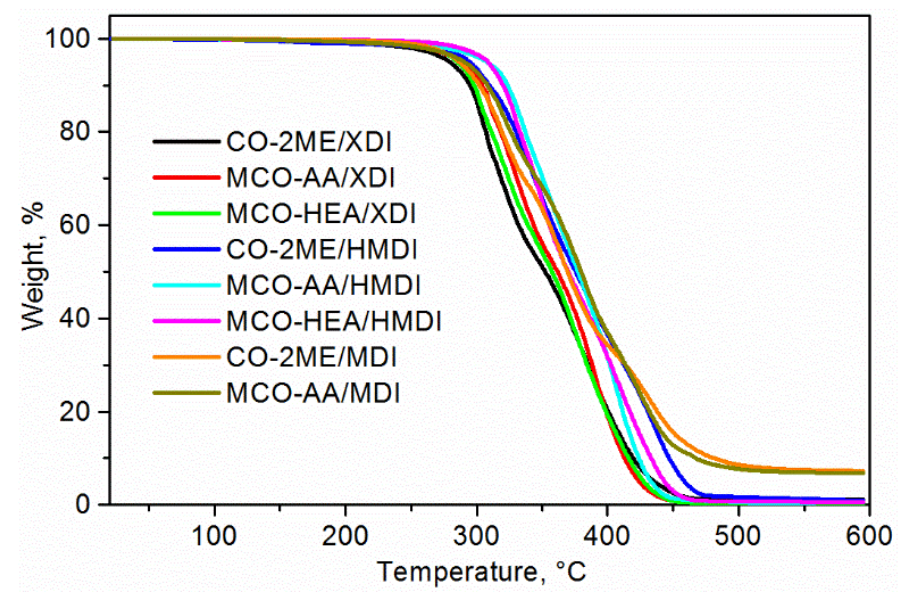

Fig.10. TGA curves of polyurethanes made from three polyols and three isocyanates.

\subsection{Rigid polyurethane foams}

Castor oil-based polyols are compatible with conventional polyether polyols for rigid foams based on sorbitol or sucrose, and can be used in blends or as sole polyols for preparation of polyurethane foams of good physical-mechanical properties. Vegetable oil-based polyols are typically used in flexible foams only in a mixture with petrochemical polyols but could be used as the sole polyols in rigid foams, if high enough in functionality. For rigid foam applications high hydroxyl numbers of polyols are required (400-500 mg KOH/g). Rigid PU foams usually employ physical blowing agents such as low boiling liquids. The somewhat lower hydroxyl number of the polyols prepared here could be compensated for by adding water which generates urea bonds while generating $\mathrm{CO}_{2}$.

Rigid polyurethane foams were prepared with castor oil-based polyols alone, using the formulation shown in Table 3. No physical blowing agent was used, since gas was generated in the water-isocyanate reaction. Formulations for rigid foams usually contain only amine catalysts, but we have used also stannous octoate to boost the reactivity of secondary hydroxyls with isocyanates. Polymeric MDI had a functionality of 2.7.

The foaming process is characterized by several phases involving nucleation of bubbles when the reaction mass turns white (cream time), foam rise due to cell expansion (rise time), gel time, and tack free time designating the end of curing. Our systems displayed fast foaming with cream 
time of around 10-15 seconds and rise time of about 52-90 s, i.e., producing well developed foams, as shown in Fig. 11. Cross-sections of the foams observed by electron microscopy, Fig. 12, reveal closed cell structure (90\%) with average cell size around $210 \mu \mathrm{m}$. Properties of rigid polyurethane foams prepared from the castor oil polyols synthesized by thiol-ene reactions are presented in Table 4.

Table 3. Formulation for the preparation of rigid PU foams

\begin{tabular}{ll}
\hline Component & pph \\
\hline Polyol & 100 \\
\hline Silicon surfactant & 2.0 \\
\hline Amine catalyst & 0.6 \\
\hline Sn-octoate & 0.2 \\
\hline water & 4.0 \\
\hline Polymeric MDI & Index 105 \\
\hline pph- parts per hundred parts of polyol
\end{tabular}

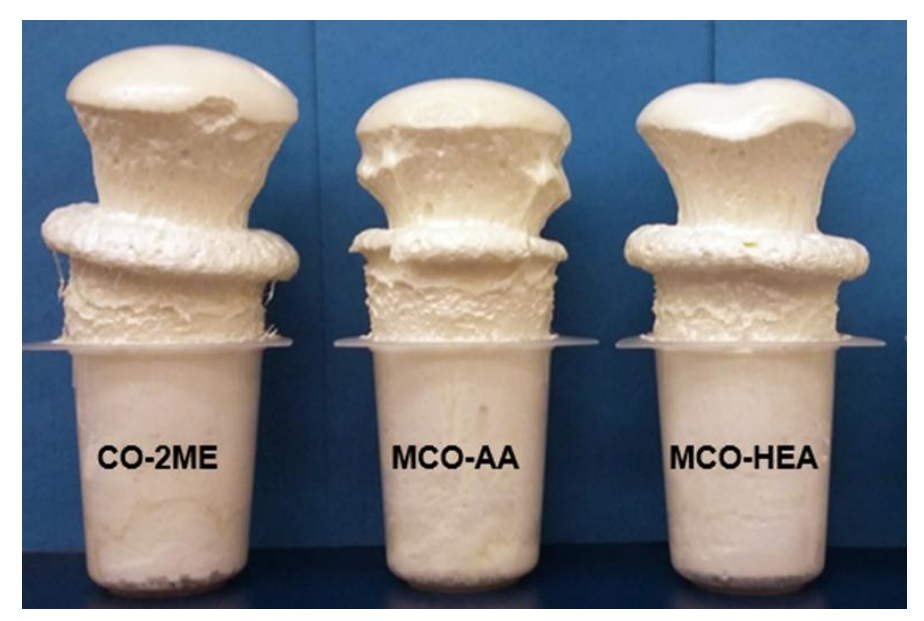

Fig.11. Images of rigid polyurethane cup foams from high functionality castor oil polyols as sole polyols. 


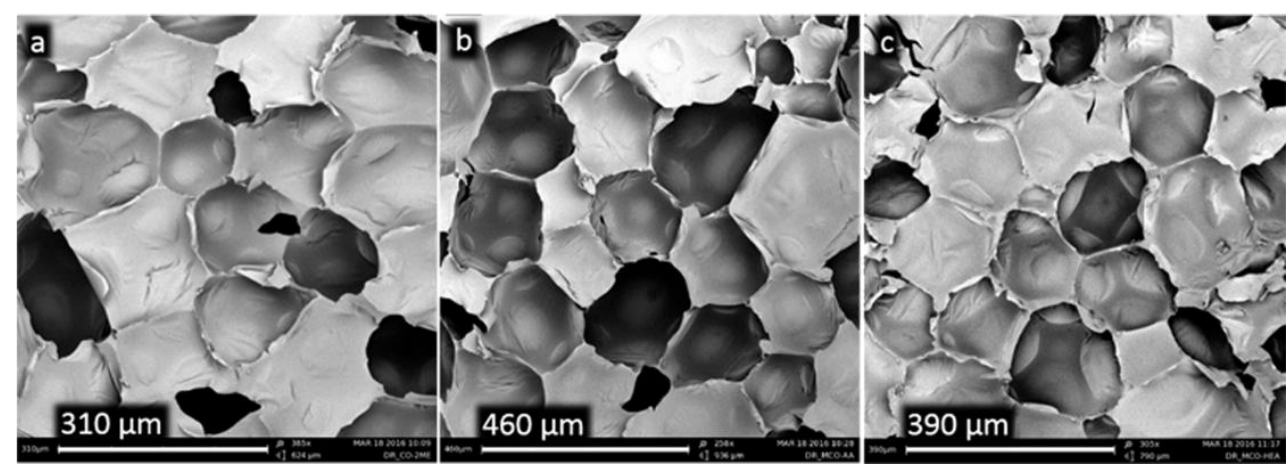

Fig. 12.SEM images of cell structure of a) CO-2ME foam, b) MCO-AA foam, and c) MCO-HEA foam.

Table 4. Properties of rigid polyurethane foams prepared from high functionality castor oil polyols

\begin{tabular}{|c|c|c|c|}
\hline FOAM ID & $\begin{array}{l}\text { Apparent } \\
\text { Density } \\
\left(\mathrm{kg} / \mathrm{m}^{3}\right)\end{array}$ & $\begin{array}{l}\text { Closed cell } \\
\text { content } \\
(\%)\end{array}$ & $\begin{array}{l}\text { Compression } \\
\text { strength @ 10\% } \\
\text { strain } \\
\text { (kPa) }\end{array}$ \\
\hline FOAM-CO-2ME & 35 & 90 & 127 \\
\hline FOAM-MCO-AA & 38 & 91 & 159 \\
\hline FOAM-MCO-HEA & 37 & 92 & 220 \\
\hline
\end{tabular}

These foams are similar to rigid foams from petrochemical polyols. The density of polyurethane foams from all three polyols was around $35 \mathrm{~kg} / \mathrm{m}^{3}$ which is somewhat higher than that required for thermal insulation $\left(32 \mathrm{~kg} / \mathrm{m}^{3}\right)$. Closed cell content of $90-92 \%$ is satisfactory for thermal insulation applications. The compression strengths for PU foams with polyols CO-2ME and MCO-AA were in the range of $127-159 \mathrm{kPa}$, which was somewhat higher than the minimum target value of $120 \mathrm{~kg} / \mathrm{m}^{3}$, as a result of higher density and higher crosslink density. The foam based on MCO-HEA, as sole polyol, had the highest compression strength of $220 \mathrm{kPa}$. 


\section{CONCLUSIONS}

Three high functionality polyols based on castor oil have been prepared by thiol-ene reactions of castor oil with 2-mercaptoethanol (photochemical thiol-ene reactions) and of mercaptanized castor oil with allyl alcohol (photochemical) and 2-hydroxyethyl acrylate (Michael thiol-ene reaction). The polyols had functionalities of 5.1-5.8 and hydroxyl numbers (OH\#) of 218-290 mg $\mathrm{KOH} / \mathrm{g}$, higher than castor oil. Cast polyurethane resins were elastomeric or leathery when cured with aliphatic diisocyanate, but moderately rigid and strong materials when cured with HMDI and MDI. They may be useful as casting compounds for electrical insulation, various mechanical parts or as binders for fiber-reinforced composites. The polyols were tested as the sole polyol in rigid polyurethane foams and demonstrated good physical and mechanical properties, suitable for use as thermal insulation in freezers, storage tanks for the chemical and food industries, building insulation and packaging, or as a wood substitute.

\section{Acknowledgment}

We are indebted to Chevron Phillips Chemical Company LP for financial support.

This work was also supported by research funding from U.S. Department of Agriculture, Award No. 2008-38924-19200. 


\section{References}

[1] Oertel G, editor, Polyurethane Handbook, Hanser Publishers, Munich, 1985.

[2] Saunders JH, Frisch K.C., Polyurethanes: Chemistry and Technology, Part II, Interscience Publishers, New York, 1964.

[3] Petrovic ZS, Polyurethanes from Vegetable Oils, Polymer Reviews 2008; 48:109-155

[4] Petrovic ZS, Javni I., Ionescu M., Biological Oils as Precursors to Novel Polymeric Materials, Journal of Renewable Materials 2013;1(3):167-186.

[5] Liu Z, Kraus G, editors, Green materials from plant oils, Royal Society of Chemistry (UK), Chapter 5, Liu F, Zhu J, Plant oil based polymeric materials and their applications 2015; 93-126.

[6] Smith PB, Payne GI, The emergence of renewable and sustainable polymers, in Renewable and sustainable polymers-American .Chemical Society Symposium Series 1063, 2011; Chapter 1, 1-10.

[7] Petrović Z.S., Yang L, Zlatanić A, Zhang W, Javni I, Network structure and properties of polyurethanes from soybean oil, J Appl Polym Sci 2007;105(5):2717-27.

[8] Ionescu M, Chemistry and technology of polyols for polyurethanes”, Edited by RAPRA, UK 2005; 435-475.

[9] Guo A, Cho Y, Petrović ZS, Structure and properties of halogenated and nonhalogenated soy-based polyols, J PolymSci: PolymChem Ed 2000;38(21): 3900-3910.

[10] Petrović ZS, Javni I, Guo A, Zhang W, 2002;US 6,433,121.

[11] Petrović ZS, Guo A, Javni, 2003; US Pat. 6,573,354.

[12] Petrović ZS, Javni I, Guo A, Zhang W, 2004; US 6,686,435.

[13] Kandanarachchi P, Guo A, Petrović ZS, The hydroformylation of vegetable oils and model compounds by ligand modified rhodium catalysis, J Molecular Catalysis A:Chemical 2002;184(1-2): 65 .

[14] Kandanarachchi P, Guo A, Demydov D, Petrović ZS, Kinetics of the hydroformylation of soybean oil by ligand-modified homogeneous rhodium catalysis, J. Amer Oil Chem Soc 2002;79(12): 1221 .

[15] Tran NB, Vialle J, Pham QT, Castor Oil Based Polyurethanes, Polymer1997; 38(10):2467. 
[16] Petrović ZS, Fajnik D, Preparation and properties of castor oil based polyurethanes, J. Appl Polym Sci 1984; 29(4): 1031-1040.

[17] Mutlu H, Meier MR, Castor oil as a renewable resource for the chemical industry", Eur J Lipid Sci Technol 2010; 112(1): 10-30.

[18] http://www.acme-hardesty.com/product/hydrogenated-castor-oil/

[19] Hoyle CE, Bowman CN, Thiol-ene click chemistry, Angew Chem Int Ed 2010; 49: 15401573.

[20] Lowe AB, Thiol-ene "click" reactions and recent applications in polymer and material synthesis, Polym Chem 2010; 1: 17-36.

[21] Lowe AB, Harvison MA, Thiol based chemistries in polymer synthesis and modification, Aust J Chem 2010; 63(8):1251-66.

[22] Bantchev GB, Kenar JA, Biresaw G, Han MG, Free radical addition of butanethiol to vegetable oil double bonds, J Agric Food Chem2009; 57: 1282-1290.

[23] Uygun M, Tasdelen MA, Yagci Y, Influence of type of initiation on thiol-ene "click" chemistry", Macromol Chem Phys 2010; 211(1): 103-110.

[24] Kade JM, Burke DJ, Hawker CJ, The power of thiol-ene chemistry. J.Polym Sci, Part A Polym Chem 2010; 48:743-50.

[25] Cramer NB, Reddy SK, O'Brien AK, Bowman CN, Thiol-ene photopolymerization mechanism and rate limiting step changes for various vinyl functional group chemistries, Macromolecules 2003; 36:7964-9.

[26] Caillol S, Desroches M, Carlotti S, Auvergne R, B. Boutevin, Synthesis of new polyurethanes from vegetable oil by thiol-ene coupling, Green Materials 2013;1(1): 16-26, [27] Caillol S, Boutevin B. Desroches M., WO2012001315.

[28] Black M, and Rawlins JW, Thiol-ene UV-curable coatings using vegetable oil macromonomers, Eur Polym J, 2009;45:1433-41.

[29] Lligadas G, Ronda JC, .Galia M, Cadiz V, Oleic and undecylenic acids as renewable feedstocks in the synthesis of polyols and polyurethanes, Polymers 2010; 2: 440-453, [30] Desroches M, Caillol S, Auvergne R, Boutevin B, Synthesis of pseudo-telechelic diols by transesterification and thiol-ene coupling, Eur J Lipid Sci Technol, 2012; 114: 84-91

[31] Lligadas G, Ronda JC, Galia M, Cadiz V, Plant oils as platform chemicals for polyurethane synthesis: current state-of-art, Biomacromolecules, 2010; 11: 2825-2835, 
[32] Desroches M, Caillol S, Lapinte V, Auvergne R, Boutevin B, Synthesis of biobased polyols by thiol-ene coupling from vegetable oils, Macromolecules, 2011; 44: 2489-2500.

[33] Ionescu M, Radojcić D, Wan X, Petrović ZS, Upshaw TA, Functionalized vegetable oils as precursor for polymers by thiol-ene reaction, Eur Polym J 2015; 67: 439-448.

[34] Gupta RK, Ionescu M, Radojcić D, Wan X, Petrović ZS, Novel renewable polyols based on limonene for rigid polyurethane foams, J.Polym Environ 2014; 22: 304-309.

[35] Ionescu M, Radojčić D, Wan X, Petrović ZS, Upshaw T, High functionality biobased polyols for rigid polyurethane foams", $106^{\text {th }}$ AOCS Annual Meeting and Industry Showcases Orlando, Florida, 4-7 May, 2015.

[36] Chan JW, Hoyle CE, Lowe AB, Bowman M, Nucleophile-initiated thiol-Michael reactions. Effect of organocatalyst, thiol and ene, Macromolecules, 2010; 43: 6381-6388.

[37] Li GZ, Randev RK, Soerivadi AH, G.Rees, Boyer C, Tong Z, Davis TP, Becer C, Haddleton DM, Investigation into thiol-(meth) acrylate Michael addition reactions using amine and phosphine catalysts, Polym Chem 2010; 1(8): 1196-1204.

[38] Petrovic ZS, Javni I, Guo A, Electroinsulating polyurethane casting resins based on soy oil and castor oil, Proceedings of the Polyurethanes EXPO'98, 1998; 559-562. 